\section{Provenance}

Commissioned; not peer reviewed.

\section{REFERENCES}

1. Department of Health. What is the European Working Time Directive?

http://www.dh.gov.uk/en/Managingyourorganisation/W orkforce/Workforceplanninganddevelopment/European workingtimedirective/DH_077304 (accessed 8 Apr 2010).

2. Royal College of Physicians. European Working Time Directive (EWTD). Why is the EWTD relevant to me? http://www.rcplondon.ac.uk/professional- issues/workforce/workforce-issues/pages/ewtd.aspx (accessed 8 Apr 2010).

3. National Confidential Enquiry into Patient Outcome and Death. Caring to the End? A review of the care of patients who died in hospital within four days of admission. http://www.ncepod.org.uk/2009dah.htm (accessed 8 Apr 2010).

4. McIntyre HF, Winfield S, Te HS, Crook D Implementation of the European Working Time Directive in an NHS trust: impact on patient care and junior doctor welfare. Clin Med 2010; 10(2): 134-137.

\section{ADDRESS FOR CORRESPONDENCE}

\section{John Black}

The Royal College of Surgeons of England, 35-43 Lincoln's Inn Fields, London WC2A 3PE.

Email: john.black@rcseng.ac.uk

\title{
Bipolar spectrum disorders in primary care: optimising diagnosis and treatment
}

Depression is an extremely common presentation in primary care and the public health importance of depressive disorders are now very well established. ${ }^{1,2}$ Patients with bipolar affective disorder (who experience episodes of depression alternating with episodes of mania or hypomania), frequently present to their GPs with difficult-to-treat depressive episodes. Indeed, for most of these patients, depressive symptoms (rather than manic symptoms) dominate the long-term clinical course of their illness.

Bipolar disorder type I (BD-I; depression alternating with mania) affects around $1 \%$ of the population and bipolar disorder type II (BD-II; depression alternating with hypomania) affects a further $2-3 \% .^{3}$ Although the clinical features of BD-I and BD-II are widely known, it is less well recognised that the boundary between bipolar disorder and recurrent unipolar depression is far from clear-cut. ${ }^{4}$ A significant proportion of patients with unipolar depression experience mild or brief episodes of hypomania which fall below the threshold for a formal diagnosis of BD-I or BD-II. ${ }^{5-7}$
These 'bipolar spectrum' patients often have patterns of depressive episodes, comorbidities, and treatment responses that differ from those with more straightforward unipolar depression and which, therefore, require a different approach to diagnosis and management. This generally under-recognised issue has far-reaching implications for the way in which clinicians, particularly GPs, approach the assessment and management of all of their depressed patients.

Within the research community, there is an emerging consensus that the diagnostic criteria for hypomania are overly restrictive and result in many patients with significant bipolar symptoms being placed within the broad diagnostic category of unipolar depression. ${ }^{7-9}$ Converging evidence from a number of studies from around the world suggests that at least $25 \%$ of patients with recurrent unipolar depression may be better classified as having a broadlydefined bipolar spectrum disorder. ${ }^{5-7,10-12}$ Importantly, these patients have similar rates of bipolar family history and comparable levels of health service use, long-term illness severity, and psychosocial morbidity as patients with bipolar disorder diagnosed according to the formal DSM-IV criteria. . $, 7,10^{\circ}$ Furthermore, certain clinical subgroups of depressed patients, such as those with an especially severe or early-onset of depression ${ }^{13,14}$ or those with treatment resistance to antidepressants, ${ }^{15}$ appear to have particularly high rates of unrecognised bipolar disorder.

For a number of reasons, BD-I and BDII disorder (and, by extension, bipolar spectrum disorder) can be very difficult to diagnose. ${ }^{16}$ Most BD-I and BD-II patients will experience a delay of several years between their first onset of significant manic symptoms and receiving the correct diagnosis, and misdiagnosis in the interim as unipolar depression, personality disorder, a primary drug or alcohol problem, or even schizophrenia is relatively common. ${ }^{16-19}$ Given that depression (rather than mania) dominates the natural history of bipolar disorder, patients are much more likely to seek help, usually from their GP, during their 
low periods. ${ }^{17,18}$ Therefore, consultations are inevitably 'depression centric' and it is not currently usual practice to systematically assess all depressed patients for a past history of manic symptoms. This problem is compounded by poor patient insight into their prior experiences of hypomania and mania and by infrequent use of corroborative histories taken from close relatives, which can often be extremely helpful for identifying previous manic symptoms. Similarly, although the use of screening questionnaires for depression, such as the Patient Health Questionnaire (PHQ), the Hospital Anxiety and Depression Scale (HADS), and the Beck Depression Inventory (BDI), is now routine in primary care, currently very few clinicians make use of available screening instruments for hypomania ${ }^{19}$ such as the Mood Disorder Questionnaire (MDQ), ${ }^{20}$ the Bipolar Spectrum Diagnostic Scale (BSDS), ${ }^{21}$ and the Hypomania Checklist (HCL-32). ${ }^{22}$ All of these instruments are relatively brief and have been validated for use in a range of clinical settings. The BSDS may be particularly useful for identifying hypomania in primary care patients with depression. ${ }^{21}$

Perhaps the most important practical issue for patients with an unrecognised bipolar spectrum disorder concerns the use of antidepressants. Recent evidence suggests that antidepressants may be of limited therapeutic benefit in the treatment of bipolar depression ${ }^{23,24}$ and may even be unhelpful by causing destabilisation of mood, ${ }^{25}$ more frequent mood episodes, ${ }^{26}$ treatment resistance, ${ }^{27}$ and possibly also (especially in young bipolar patients) an increase in suicidal behaviour. ${ }^{28-30}$ Although caution is required when extrapolating findings from studies of BD-I and BD-II patients to groups of patients with broadly-defined bipolar spectrum conditions, the principle of 'first do no harm' should guide decisions on the use of antidepressants in this group. Unfortunately (largely due to the reluctance of drug companies and nonindustry research funders to investigate diagnoses which go beyond formally accepted categories) there have been very few studies, to date, which have assessed the risks and benefits of antidepressants in patients with broadlydefined bipolar depression. ${ }^{31}$

A pragmatic approach to this problem is to consider avoiding antidepressants in depressed individuals where they have previously been unhelpful on several occasions (either because of lack of response or adverse effects) and instead consider treatments that are known to be effective for bipolar depression, such as lamotrigine or quetiapine. ${ }^{32}$ This is not to say that these medications should be prescribed without careful consideration. Lamotrigine has been (rarely) associated with serious skin reactions and quetiapine, as an antipsychotic, can carry quite a high side-effect burden for some patients. Where there is no clear history of poor or adverse response to antidepressants these could be prescribed, but this should always be with mood stabiliser 'cover' and the antidepressant should be withdrawn within 3 months of recovery from the depressive episode (to avoid inducing hypomania, mania, or more rapid cycling of mood episodes). ${ }^{32,33}$

In the UK, the current focus of secondary care psychiatric services is on the management of individuals with severe and enduring mental illnesses such as schizophrenia or BD-I. Depressive disorders, including those which prove to be relatively treatmentrefractory, are increasingly managed solely by GPs. Given that many of these patients may have an unrecognised bipolar spectrum disorder, diagnostic and clinical management input from secondary care would seem to be appropriate. However, in many parts of the country it is difficult for GPs to obtain comprehensive psychiatric assessments on their difficult-to-treat depressed patients and this seems unlikely to change within the near future. Therefore, it is likely to be important for the future that GPs develop competencies in the assessment, diagnosis, and treatment of bipolar depression.

In summary, broadly-defined bipolar disorders are relatively common in both primary and secondary care settings but are often not recognised or diagnosed. This issue is not simply one of academic interest but has important implications for the way that clinicians approach the assessment and management of all recurrently depressed patients, especially those patients who have complex presentations or have not responded well to at least two courses of antidepressant therapy. Changes in the organisation and delivery of psychiatric services in recent years have meant that GPs are managing more and more patients with complex depressive disorders, many of whom may have an undiagnosed bipolar disorder. GPs, as the first port of call for most of these patients, should be aware of the possibility that a significant proportion (especially those with early-onset or treatment resistant depression) may have a primary bipolar disorder. In the future, guidance on screening for bipolar disorders and appropriate management strategies for bipolar depression needs to be made more widely available. In the longer term, it is hoped that a systematic and tailored approach to this under-recognised problem may yield significant benefits in terms of early diagnosis and improved long-term management of recurrent depression for large numbers of patients.

\section{Daniel J Smith,}

Clinical Senior Lecturer and Honorary Consultant Psychiatrist, Department of Psychological Medicine and Neurology, Cardiff University School of Medicine, Cardiff.

\section{Ajay Thapar,}

Research Associate and GP, Department of Primary Care and Public Health, Cardiff University School of Medicine, Cardiff.

\section{Sharon Simpson,}

Senior Research Fellow, Department of Primary Care and Public Health, Cardiff University School of Medicine, Cardiff.

\section{Provenance}

Freely submitted; peer reviewed.

\section{REFERENCES}

1. Murray CJ, Lopez AD. Alternate projections of mortality and disability by cause 1990-2020: global burden of disease study. Lancet 1997; 349: 1498-1504.

2. Ustün TB, Ayuso-Mateos JL, Chatterji S, et al. Global burden of depressive disorders in the year 2000. Br J Psychiatry 2004; 184(5): 386-392.

3. Goodwin FK, Jamison KR. Manic-depressive illness: bipolar disorders and recurrent depression. 2nd edn. New York, NY: Oxford University Press, 2007.

4. Angst J. The bipolar spectrum. Br J Psychiatry 2007; 190(3): 189-191.

5. Angst J, Gamma A, Bennazzi F, et al. Toward a redefinition of subthreshold bipolarity: epidemiology 
and proposed criteria for bipolar-II, minor bipolar disorders and hypomania. J Affect Disord 2003; 73: 133-146.

6. Merikangas K, Akiskal, HS, Angst, J, et al. Lifetime and 12-month prevalence of bipolar spectrum disorder in the National Comorbidity Survey Replication. Arch Gen Psychiatry 2007; 64(5): 543-552.

7. Zimmermann P, Bruckl T, Nocon A, et al. Heterogeneity of DSM-IV major depressive disorder as a consequence of subthreshold bipolarity. Arch Gen Psychiatry 2009; 66(12): 1341-1352.

8. Smith DJ, Ghaemi SN, Craddock N. The broad clinical spectrum of bipolar disorder: implications for research and practice. Journal of Psychopharmacology 2008; 22: 397-400.

9. Ghaemi SN, Michael B, Frederick C, et al. Diagnostic guidelines for bipolar disorder: a summary of the International Society for Bipolar Disorders Diagnostic Guidelines Task Force Report. Bipolar Disorders 2008; 10(1p2): 117-128.

10. Judd LL, Akiskal HS. The prevalence and disability of bipolar spectrum disorders in the US population: reanalysis of the ECA database taking into account subthreshold cases. J Affect Disord 2003; 73: 123-131.

11. Akiskal HS, Akiskal KK, Lancrenon S, et al. Validating the bipolar spectrum in the French National EPIDEP Study: overview of the phenomenology and relative prevalence of its clinical prototypes. J Affect Disord 2010; in press.

11. Angst J, Sellaro R, Stassen HH, Gamma A. Diagnostic conversion from depression to bipolar disorders: results of a long-term prospective study of hospita admissions. J Affect Disord 2005; 84(2-3): 149-157.
13. Geller B, Zimmerman B, Williams M, et al. Bipolar disorder at prospective follow-up of adults who had prepubertal major depressive disorder. Am J Psychiatr 2001; 158: 125-127.

14. Smith DJ, Harrison N, Muir W, Blackwood DHR. The high prevalence of bipolar spectrum disorders in young adults with recurrent depression: toward an innovative diagnostic framework. J Affect Disord 2005; 84(2-3): 167-178.

15. Sharma V, Khan M, Smith A. A closer look at treatment resistant depression: is it due to a bipola diathesis? J Affect Disord 2005; 84(2-3): 251-257.

16. Smith DJ, Ghaemi SN. Is underdiagnosis the main problem with diagnosing bipolar disorder? Yes. $B M J$ 2010: 340: c854. doi: 10.1136/bmj.c854.

17. Judd LL, Akiskal HS, Schettler PJ, et al. The long-term natural history of the weekly symptomatic status of bipolar i disorder. Arch Gen Psychiatry 2002; 59(6): 530-537.

18. Judd LL, Akiskal HS, Schettler P, et al. A prospective investigation of the natural history of the long-term weekly symptomatic status of bipolar II disorder. Arch Gen Psychiatry 2003; 60(3): 261-269.

19. Allen R, Smith DJ. Screening for bipolar disorder: strengths and limitations of currently available instruments. Prim Care Community Psychiatr 2008; 13(2): 47-51.

20. Hirschfeld RMA, Cass AR, Holt DCL, Carlson CA. Screening for bipolar disorder in patients treated fo depression in a family medicine clinic. J Am Board Fam Pract 2005; 18(4): 233-239.

21. Phelps JR, Ghaemi SN. Improving the diagnosis of bipolar disorder: predictive value of screening tests. $J$
Affect Disord 2006; 92(2-3): 141-148.

22. Angst J, Adolfsson R, Benazzi F, et al. The HCL-32: Towards a self-assessment tool for hypomanic symptoms in outpatients. J Affect Disord 2005; 88(2): 217-233.

23. Sachs GS, Nierenberg AA, Calabrese JR, et al. Effectiveness of adjunctive antidepressant treatment for bipolar depression. N Engl J Med 2007; 356(17): 1711-1722.

24. McElroy S, Young AH, Carlsson A, et al. A doubleblind placebo-controlled study with acute and continuation phase of quetiapine and paroxetine in adults with bipolar depression (Embolden II). Bipolar Disorders 2008; 10: 59 .

25. Goldberg JF, Truman C. Antidepressant-induced mania: an overview of current controversies. Bipolar Disorders 2003; 5: 407-420.

26. El-Mallakh RS, Karippot A, Ghaemi, SN Antidepressants in bipolar depression. In: Ghaemi SN El-Mallakh RS (eds). Bipolar depression. Washington, DC: American Psychiatric Publishing 2006; 167-183.

27. Sharma V, Khan M, Smith A. A closer look at treatment resistant depression: is it due to a bipolar diathesis? J Affect Disord 2005; 84(2-3): 251-257.

28. Dilsaver SC, Chen YW, Swann AC, et al. Suicidality in patients with pure and depressive mania. Am J Psychiatry 1994; 151(9): 1312-1315.

29. Akiskal HS, Mallya G, Benazzi F, et al. Agitated 'unipolar' depression re-conceptualized as a depressive mixed state: implications for the antidepressantsuicide controversy. J Affect Disord 2005; 85(3): 245-258.

30. Berk M, Dodd S. Are treatment emergent suicidality and decreased response to antidepressants in younger patients due to bipolar disorder being misdiagnosed as unipolar depression? Medical Hypotheses 2005; 65(1): 39-43.

31. Smith DJ, Forty L, Russell E, et al. Sub-threshold manic symptoms in recurrent major depressive disorder are a marker for poor outcome. Acta Psychiatr Scand 2009; 119(4): 325-329.

32. Goodwin GM. Evidence-based guideline for treating bipolar disorder. Revised second edition recommendations from the British Association for Psychopharmacology. Journal of Psychopharmacology 2009: 1-43.

33. National Institute of Health and Clinical Excellence. Bipolar disorder: the management of bipolar disorder in adults, children and adolescents, in primary and secondary care. http://www.nice.org.uk/CG038 (accessed 31 Mar 2010).

DOI: 10.3399/bjgp10X484165
Daniel J Smith

Department of Psychological Medicine and Neurology, Cardiff University School of Medicine, Monmouth House, Heath Park, Cardiff CF14 4DW. Email:SmithDJ3@Cardiff.ac.uk 